\title{
CONTRACTUAL CHOICE IN APARTMENT MARKETS: THE ROLE OF ECONOMIC AND INSTITUTIONAL FACTORS IN KOREA
}

Travis K. Taylor, Christopher Newport University, Newport News, VA, USA

Wonseok Woo, Ewha Women's University, Seoul, South Korea

dx.doi.org/10.18374/JIBE-13-1.6

\begin{abstract}
Apartment rental contracts vary considerably across the world. The ubiquitous monthly rent plus security deposit is the standard contract in the United States and many Western countries. In Asia, apartment landlords employ a variety of contracting methods that can be explained by economic and cultural factors. Frequently, large sums of money will be paid in advance by the tenant in lieu of monthly rents. This paper juxtaposes apartment contracting methods in the U.S. and South Korea. A model is developed to analyze contractual choice in Korea, and ascertain the degree to which landlords and tenants respond to economic and institutional factors.
\end{abstract}

Keywords: contracting; housing, institutions, Korea, international 